\title{
Estresse Ocupacional em Profissionais do Serviço de Atendimento Móvel de Urgência (SAMU)
}

Occupational Stress in Professionals of Urgent Mobile Care Service (SAMU)

Estrés laboral en Profesionales del Servicio de Atención Móvil de Urgencia (SAMU)

\author{
Daiane Granada Martins ${ }^{1}$ \\ Centro Universitário Franciscano
}

Júlia Gonçalves

Universidade Federal de Santa Catarina

\begin{abstract}
Resumo
O trabalho constitui um dos principais fatores desencadeantes do estresse, que se apresenta de modo intenso em profissionais da saúde pública. Objetivou-se identificar o estresse de trabalhadores do Serviço Móvel de Urgência (SAMU), investigar o conhecimento acerca do fenômeno e conhecer suas vivências de trabalho. Utilizaram-se o Inventário de Sintomas de Stress para Adultos de LIPP e uma entrevista individual. O uso inadequado do serviço pela população e a falta de autonomia dos socorristas foram apontados como fatores estressantes pelos profissionais entrevistados. Identificouse que há certo desconhecimento desses profissionais, mesmo sendo trabalhadores da saúde, acerca do fenômeno estresse. Dentre as estratégias utilizadas pelos trabalhadores para lidar com as situações cotidianas, estão a prática de atividade física, a convivência com a família, o gosto pelo trabalho realizado e o fenômeno da habituação. Pode-se constatar que a integridade física e mental dos sujeitos investigados reflete positivamente no atendimento prestado junto à comunidade.

Palavras-chave: saúde mental, estresse, profissionais da saúde
\end{abstract}

\begin{abstract}
Work is one of the main triggers of stress, which appears more intensely in public health professionals. This research aimed to identify the stress of workers of the Mobile Emergency Service (SAMU), to investigate the knowledge of these professionals about the stress and know their work experiences. We used the LIPP's Stress Symptoms Inventory for Adults and an individual interview. The inadequate use of the service by the population and the lack of autonomy of the first responders were pointed out as stressing factors by the professionals interviewed. The study identified a lack of knowledge about the stress phenomen by these professionals, even being health workers. The resources used by workers to cope with everyday situations are the practice of physical activity, family conviviality, sense of accomplishment by the work performed and the habituat phenomenon. We conclude that the physical and mental integrity of the investigated subjects reflects positively on the care provided to the community.
\end{abstract}

Keywords: mental health, stress, health professional

\section{Resumen}

El trabajo constituye uno de los principales factores desencadenantes de estrés, que aparece con mayor intensidad en los profesionales del área de la salud pública. Su objetivo fue identificar el estrés de los trabajadores del Servicio de Atención Móvil de Urgencia (SAMU), investigar el conocimiento sobre el estrés que tienen estos profesionales y conocer sus experiencias laborales. Se utilizó el Inventario de Síntomas de Estrés para Adultos de LIPP (ISSL) y una entrevista individual. El uso inadecuado del servicio por la población y la falta de autonomía de los equipos de rescate fueron identificados como factores de estrés por los profesionales entrevistados. Se identificó que existe una cierta falta de conocimiento de estos profesionales, incluso siendo trabajadores de la salud, sobre el fenómeno denominado estrés. Los recursos utilizados por los trabajadores para hacer frente a situaciones cotidianas incluyen la práctica de actividad física, la vida familiar, el gusto por la labor realizada y el fenómeno de la habituación. Se puede constatar que la integridad física y mental de los sujetos investigados se refleja positivamente en la atención ofrecida a la comunidad.

Palabras clave: salud mental, estrés, profesionales de la salud

\footnotetext{
${ }^{1}$ Endereço de contato: Rua João Atílio Zampieri, n. 215, apto. 402, Bairro Camobi, Santa Maria, RS - CEP 97105-490. E-mail: daianegranada@hotmail.com
} 


\section{Introdução}

O pressuposto da centralidade do trabalho (Antunes, 2003) considera que este ocupa uma parte significativa na vida dos indivíduos e mostra-se fundamental para o processo de identidade e de socialização do ser humano. Para as ciências sociais, o trabalho é remunerado financeira e socialmente, ou seja, o ato de trabalhar revela-se também como um fator de inserção e de integração entre os seres humanos no seu meio social. O trabalho altera o homem e modifica suas maneiras de agir sobre o mundo, bem como seus modos de pensar e de sentir (Souza et al., 2011). O trabalho humano inclui intencionalidade e é intermediado pela cultura (Borges \& Yamamoto, 2014), isto reflete na liberdade de escolha por sua atividade laboral, de acordo com preferências e interesses. Entretanto essa liberdade não implica, necessariamente, ausência de insatisfações e de sofrimentos ligados ao trabalho.

Com o crescente processo de automação do trabalho aliado aos novos modelos de gerenciamento, iniciados na década de 1970, houve um deslocamento no eixo de exigências postas para os trabalhadores. Não foi descartada a demanda pela capacidade física do trabalhador, porém houve um aumento significativo da capacidade psíquica, sendo sobre essa dimensão do trabalhador que recai o maior impacto do trabalho (Borges \& Yamamoto, 2014). Essas transformações exigem um contínuo processo de adaptação, que produz gasto de energia e, consequentemente, desgaste do organismo (Lipp \& Malagris, 2011).

Ao observar essa relação com o trabalho em profissionais que atuam no cuidado ao outro, nota-se que estes estão bastante suscetíveis ao desgaste psíquico e ao adoecimento decorrente da vida ocupacional. A prática da assistência, que leva o profissional ao contato direto com o sofrimento do outro, o torna mais vulnerável ao estresse, trazendo prejuízos não só à sua saúde, mas também à qualidade da assistência prestada (Sousa \& Araújo, 2015; Adriano et al., 2017). Fazem parte desse grupo os socorristas do Serviço de Atendimento Móvel de Urgência (SAMU), categoria profissional que está exposta a situações de intensa tensão e ansiedade, pois possuem como objeto de trabalho indivíduos portadores de casos clínicos graves, muitas vezes em risco de morte iminente. Somadas a isso, tem-se, muitas vezes, a precariedade dos recursos de trabalho e as peculiaridades inerentes aos serviços de emergência, tais como os riscos biológicos, químicos e ergonômicos, além do trabalho se realizar por turnos. O grau e o tipo de exposição diária a que profissionais de emergência pré-hospitalar estão sujeitos, bem como o contexto e suas condições de trabalho, constituem-se fatores de risco para a saúde mental e o bem-estar psicológico desses trabalhadores. Além do estresse ocupacional, os socorristas são mais comumente acometidos por transtorno do estresse pós-traumático, ansiedade, depressão e perda do controle emocional e comportamental (Marcelino, Figueiras, \& Claudino, 2012).

O estresse ocupacional pode ser definido com ênfase nos fatores de trabalho que extrapolam a capacidade de enfrentamento do indivíduo (estressores organizacionais) ou nas respostas fisiológicas, psicológicas e comportamentais dos indivíduos aos estressores. O estresse ocupacional é considerado como um processo concebido por estressores e respostas e, sobretudo, como um conceito relacional, que enfoca a relação entre o ambiente de trabalho e o sujeito. Esse fenômeno é decorrente da avaliação do indivíduo das demandas do trabalho como sendo excessivas para os recursos de enfrentamento que possui. Assim, o estresse não seria apenas da ordem particular do sujeito, mas algo que se desenvolve a partir 
da conjunção de um determinado ambiente com um tipo particular de pessoa (Paschoal \& Tamayo, 2005).

O estresse pode ocasionar prejuízos no desempenho global do indivíduo, ou seja, problemas na saúde física e mental, repercutindo em sua atuação profissional, bem-estar e relações interpessoais (Pereira, Miranda, \& Passos, 2010). Este estudo teve como objetivos identificar se os trabalhadores do SAMU, de uma cidade do interior do Rio Grande do Sul, apresentavam quadros de estresse, bem como investigar o conhecimento desses profissionais sobre o fenômeno e conhecer suas vivências de trabalho consideradas estressantes.

\section{Método}

Para a realização desta pesquisa, foi adotada uma abordagem qualitativa do objeto a ser estudado. As pesquisas qualitativas, especialmente na área da saúde, visam compreender as relações e as representações que os indivíduos fazem a respeito do modo como vivem e constroem seus artefatos e a si mesmos, como sentem e como pensam (Minayo, 2010).

Participaram da pesquisa quatro trabalhadores do SAMU, sendo um médico, um enfermeiro, um técnico de enfermagem e um condutor, que foram identificados aleatoriamente por P1, P2, P3 e P4. Três participantes eram do sexo masculino e um do sexo feminino, com idades entre 31 e 52 anos e tempos de serviço que variavam entre dois e três anos. A carga horária de trabalho semanal é de 40 horas em regime de plantão. Embora o serviço em que se realizou a pesquisa contasse com 44 trabalhadores, a opção de realizar a coleta de dados com quatro profissionais, um participante de cada um dos quatro cargos existentes no serviço, deve-se ao intuito de adquirir maior familiaridade com o problema, com vistas a torná-lo mais explícito e construir hipóteses para futuras pesquisas e intervenções. Todos os profissionais do serviço atuam como socorristas, mesmo que possuindo diferentes atribuições e responsabilidades, dependendo da formação específica. Para participar da pesquisa, os trabalhadores deveriam estar atuando no serviço por pelo menos um ano e na respectiva função dentro do SAMU. A escolha ocorreu de forma aleatória conforme interesse e disponibilidade, sendo que não pertenciam, necessariamente, à mesma equipe. Trata-se de uma amostra não probabilística por conveniência, em que não se pretende generalizar os resultados encontrados para a população como um todo.

Utilizou-se para a coleta dos dados o Inventário de Sintomas de Stress para Adultos de Lipp - ISSL (Lipp, 2005) baseado no modelo quadrifásico. Esse questionário é de fácil aplicação e visa avaliar o grau de estresse (fase de estresse em que o indivíduo se encontra) e investigar se os sintomas existentes se manifestam nas áreas somática ou psíquica. É composto por três quadros referentes às fases de estresse: alerta, resistência (e quase-exaustão) e exaustão. Os sintomas físicos (F) e psicológicos (P) que aparecem em cada quadro são os típicos de cada fase. Esse instrumento foi utilizado em uma fase de exploração da amostra, buscando conhecer se esses participantes possuíam sintomas que configurassem um quadro de estresse. Após a aplicação do ISSL, agendou-se um segundo encontro, conforme a disponibilidade de cada participante, para a realização de uma entrevista individual semiestruturada. Nessa modalidade de entrevista, existe um número de elementos a serem investigados, mas que vão se desenvolvendo de acordo com o entrosamento estabelecido com o investigado (Breakwell, Fife-Schaw, Hammond, \& Smith, 2010). Dentre os exemplos de 
questões de referência para a condução da entrevista estão: "No seu entendimento, o que é o estresse?", "Descreva os sintomas que você considera como sendo do estresse" e, "No seu cotidiano de trabalho, quais são as situações com maior potencial para o desencadeamento do estresse?". Logo após a entrevista, solicitou-se que cada entrevistado respondesse a um questionário de dados sociodemográficos, que foi aplicado com a finalidade de proporcionar conhecimento sobre os entrevistados.

Todos os encontros com os socorristas aconteceram após a autorização formal da direção do hospital sede do SAMU e da coordenação do serviço, na base do SAMU da cidade em que se realizou a pesquisa e no horário de trabalho dos socorristas, e tiveram, em média, uma hora de duração. Os participantes foram informados a respeito dos objetivos da pesquisa e assinaram o Termo de Consentimento Livre e Esclarecido. A pesquisa foi aprovada pelo Comitê de ética em pesquisa (no do parecer 552.391) e seguiu os preceitos previstos na Resolução no 466, de 12 de dezembro de 2012, do Conselho Nacional de Saúde (CNS) que regulamenta a pesquisa com seres humanos.

Para a análise dos dados provenientes do ISSL, optou-se pela interpretação de acordo com as instruções contidas no manual do próprio instrumento (Lipp, 2005). É importante destacar que, mesmo com a opção da utilização de um instrumento de coleta quantitativo, a análise dos dados resultantes prezou por uma interpretação qualitativa. Dessa forma, as informações advindas do inventário utilizado fomentaram e auxiliaram no entendimento das características e peculiaridades de cada participante. Já as entrevistas foram transcritas e submetidas à análise de conteúdo, seguindo as três etapas previstas: (1) Pré-análise: em que se realizou a organização do material; (2) Exploração do material: em que foram identificadas as categorias em função do conteúdo da fala dos participantes; (3) Tratamento dos resultados e interpretação: em que foram realizadas inferências e interpretações (Minayo, 2010). Dessa forma, buscou-se aproximar os achados em categorias, que receberam um suporte dos referenciais bibliográficos que discutem as temáticas: saúde mental, trabalho e estresse.

Com a análise dos dados coletados, emergiram três categorias. A primeira, denominada "Sintomas do estresse", propõe-se a identificar se os socorristas do SAMU apresentam sintomas de estresse e discute acerca do conhecimento que possuem sobre o fenômeno; essa constatação ocorreu através da interpretação do ISSL e das entrevistas. A segunda categoria, "Os agentes estressores", apresenta as vivências diárias no trabalho dentro do SAMU, e, na última categoria, "As estratégias de defesa", são expostos os recursos utilizados para enfrentar as tensões provenientes do trabalho.

\section{Sintomas do Estresse}

O conceito de "stress" foi proposto, inicialmente, pelo médico Hans Selye em 1936, para designar um conjunto de reações específicas que ele havia observado em pacientes que possuíam diferentes patologias. A definição inicial considerava a reação do estresse como uma síndrome geral de adaptação. Posteriormente foi redefinida para uma resposta não específica do corpo a qualquer exigência, evento ou circunstância ao qual este seja submetido, seja ele físico ou mental (Lipp \& Malagris, 2011). Quando as exigências do ambiente persistem além da capacidade de adaptação do indivíduo e este não consegue superar as adversidades do ambiente em que se encontra, emergem as patologias (Souza et al., 2011). 
Situações estressantes não se constituem, necessariamente, como patológicas, visto que é natural que o ser humano vivencie desconfortos ocasionais em certos momentos da vida e que estejam dentro dos sintomas considerados como sendo do quadro de estresse. Porém sintomas isolados não devem ser interpretados como possuidores de significado clínico para o diagnóstico do estresse; para a identificação da patologia, é necessária a presença de um amplo quadro de sintomas, que se prolongam por um determinado período de tempo (Lipp, 2005).

Três profissionais, participantes da pesquisa, não apresentaram quadro de estresse, apesar de considerarem suas ocupações como geradoras de ansiedade. Esta pode ser entendida como um sentimento vago e desagradável de medo, apreensão, caracterizado por tensão ou desconforto, é um estado emocional com componentes psicológicos e fisiológicos que faz parte das experiências humanas (Schmidt, Dantas, \& Marziale, 2011). As seguintes falas são exemplos ". . . Quer queira ou não, o nosso trabalho é tenso, tu está sempre esperando o telefone tocar e não sabe o que vai acontecer" (P. 1) e ". . Acidentes com vítimas politraumatizadas e situações de parada cardiorrespiratória são situações que geram um pouco de estresse porque a vítima é grave, tu tem que estabilizar essa vítima e levar até um pronto atendimento, até um local de referência" (P. 2). Esse resultado corrobora os obtidos por Adriano et al. (2017) em sua pesquisa com profissionais do SAMU de um município da Paraíba. No estudo, os autores constataram que uma alta porcentagem de trabalhadores investigados não apresentava estresse (62,5\%). Dentre as hipóteses levantadas para explicar esse resultado, destacam-se a baixa idade dos participantes e o medo de perseguição e da perda do emprego, já que na instituição não existem profissionais efetivos e a seleção é realizada através de indicação política.

Conforme os resultados indicados no ISSL, apenas a participante do sexo feminino apresentou sintomas que configurariam um quadro de estresse. Identificou-se que esses sintomas são predominantemente psicológicos e que a trabalhadora encontrava-se na fase denominada resistência, que sucede o estágio inicial, conhecido como alarme. Nessa fase, o organismo tenta recompor o seu equilíbrio interno, através da reparação dos danos ocasionados pela fase de alarme. Caso o estímulo estressor continue, tem início a terceira fase, denominada quase exaustão, que provoca maiores prejuízos ao organismo, uma vez que as doenças tendem a se desenvolver (Seleghim, Mombelli, Oliveira, Waidman, \& Sonia, 2012).

A diferença de gênero exerce influência no processo de desencadeamento do estresse. Uma das explicações para essa diferença está no fato de que as mulheres, de modo geral, desempenham vários papéis sociais e assumem, muitas vezes, uma dupla ou até tripla jornada de trabalho (Adriano et al., 2017). Muitas mulheres têm um ou mais empregos e ainda precisam cuidar do lar e dos filhos, quando os possuem. Assim, não se pode relacionar o nível de estresse apenas à área de atuação profissional, devendo-se, ainda, considerar outras variáveis (Silva \& Martinez, 2005). A questão hormonal aparece como um dos fatores que contribuem para que o sexo feminino sofra mais com a influência do estresse, uma vez que o estrogênio e a progesterona aumentam a resposta do organismo a esse fenômeno e, consequentemente, conferem maior suscetibilidade à depressão e à ansiedade (Calais, Andrade, \& Lipp, 2003). Os representantes do sexo masculino, por sua vez, podem demonstrar uma tendência a permanecerem calados e não expressarem seus sentimentos (Oliveira 
\& Lipp, 2009). Esse dado leva a inferir que as mulheres podem não ser mais estressadas do que os homens, e sim que possuem uma tendência a relatarem e expressarem mais seus sentimentos.

Quanto aos sintomas de estresse, estes aparecem de forma ampla, podendo variar de uma simples sensação de desconforto a um total esgotamento físico e mental, afetando a saúde, a qualidade de vida e a sensação de bem-estar geral. As principais consequências do estresse ocupacional são o absenteísmo, as licenças médicas, a queda na produtividade, a depressão e a dependência por fármacos (Sadir, Bignotto, \& Lipp, 2010). Entre os participantes, os sintomas descritos foram tanto da ordem somática quanto psíquica, porém não foram relatados prejuízos à qualidade do atendimento prestado, já que estes não apresentam faltas ao trabalho nem transparecem pouca motivação diante das suas atividades laborais. O participante 4 ilustra alguns sintomas: ". . . existe a queda de cabelo, as unhas fracas... . eu noto depois que comecei a trabalhar no SAMU. ... Às vezes tenho vontade de largar tudo, 'não quero mais, não venho mais', mas paro e penso "o paciente não tem culpa".

Os participantes também citaram sintomas físicos como boca seca, insônia, cansaço constante, tensão muscular, mudança de apetite, aumento da sudorese, aperto da mandíbula (bruxismo), taquicardia, problemas dermatológicos, tontura e tiques. Entre os sintomas psicológicos, destacaram-se a mudança de motivação, problemas com a memória, emotividade excessiva, irritabilidade, diminuição da libido e ansiedade diária. Esses relatos, acrescidos dos resultados do inventário (ISSL), evidenciaram ausência ou nível baixo de estresse. Com isso, pode-se inferir que o estresse enfrentado por essa categoria profissional não ultrapassa a fase de alerta do fenômeno. Esse aspecto pode ser identificado nos trechos de fala a seguir: ". . . não nos envolvendo muito com o paciente ... tu chega, dá o primeiro atendimento, estabiliza o paciente e remove, por exemplo, para um CTI ou pronto atendimento. Diferente de quem trabalha no intra-hospitalar, que convive com o paciente diariamente" (P. 2).

Nessa atividade de emergência a gente passa sempre por aquele nível de estresse, ele vem por você achar que pode perder o controle da situação, isso gera um estresse na hora. Então esse estresse tem que ser dominado pra que você possa raciocinar e fazer a coisa (P. 3).

Nessas falas, percebe-se que a tensão ocorre, principalmente, até a estabilização da vítima, que constitui a fase de alerta, que é uma preparação do organismo para a luta ou a fuga, uma vez que se encontra diante do estímulo estressor. Porém a fase seguinte do fenômeno, de resistência, não tem início e, assim, o estresse não atinge o último estágio, fase de exaustão, na qual ocorre o aparecimento de doenças orgânicas, devido ao consumo exagerado de energia na tentativa de adaptação aos eventos estressores (Fontana \& Siqueira, 2009). Esses trabalhadores se mantêm em um bom nível de saúde, pois o estresse vivenciado por eles não ultrapassa a primeira fase, uma vez que, após a estabilização da vítima, a ansiedade decorrente do atendimento é diminuída ou sanada. Além disso, situações de extrema ansiedade são intercaladas por outras capazes de gerar grande prazer aos trabalhadores, como pode ser observado na fala do participante 2, "Não pegamos somente tragédias, nós pegamos coisas boas também. Tem situações que realmente te trazem muita satisfação, que não são situações graves, mas que dá um outro 'up', quando pega um parto, por exemplo".

As entrevistas permitiram identificar um desconhecimento da definição de estresse. Para 
dois participantes o conceito em questão é confundido com crise de irritação, ou seja, o termo "estresse" é utilizado para designar um estado de "explosão" na relação interpessoal com colegas de trabalho e com os usuários do serviço, como ilustra a fala do participante 4, "Não me considero estressado, vejo que os outros estressados descarregam no colega, no próprio atendimento, são irritados. Sou bem tranquilo e calmo ... eu guardo pra mim".

A observação acerca do entendimento equivocado do conceito de estresse é frequente nos dias atuais, uma vez que a imprecisão do termo ocorre tanto no uso popular como na produção do conhecimento científico. O termo se popularizou de tal forma que ninguém o desconhece ou deixa de usá-lo em algum momento da vida e com os mais diversos significados. Essa popularização mostra-se positiva se considerarmos que muitos estudos acerca do fenômeno passaram a ocorrer e que, ainda, a maioria das pessoas tornaram-se capazes, de certa forma, de lidar com o problema. Contrariamente, o uso indiscriminado do termo é responsável pela transformação em algo genérico, que tudo explica e tudo resolve, posto que tudo é passível de desencadeá-lo (Codo, Soratto, \& Menezes, 2004).

\section{Os Agentes Estressores}

Os agentes estressores são estímulos ou eventos capazes de gerar estresse. Quando são percebidos como ameaçadores causam alterações psicofisiológicas e são capazes de quebrar a homeostase do organismo, deixando-o vulnerável a patologias. Tais agentes podem ser de ordem física, química, biológica e psicossocial, obrigando o corpo a organizar-se para que consiga adaptar-se às situações. Podem ser externos ao organismo, relacionados às vivências do cotidiano, ou internos, que se referem às características de personalidade e às formas como são interpretadas as situações (Meneghini, Paz, \& Lautert, 2011).

Os estressores ocupacionais relacionam-se a situações que os trabalhadores experienciam em suas rotinas laborais, ou seja, vivências consideradas ameaçadoras e capazes de trazer prejuízo à sua interação com o ambiente de trabalho. Estes estão presentes quando há demandas excessivas e o trabalhador não possui recursos adequados para lidar com elas (Pereira, Miranda, \& Passos, 2010). Os estressores são percebidos de acordo com características individuais, dessa forma, uma mesma situação não é considerada estressante para todos os indivíduos, assim como a magnitude ou impacto do evento estressante varia de acordo com a avaliação que o sujeito faz do acontecimento. Somam-se ainda, os recursos que cada um possui para lidar com tais estressores (Talarico, Carmelli, Nitrini, \& Chaves, 2009).

Nas entrevistas, identificaram-se os agentes estressores comuns entre os socorristas do SAMU. Para os quatro participantes, o que causa maior desgaste na rotina laboral é o contato com os usuários, que, muitas vezes, são desrespeitosos com os profissionais. Esse aspecto mostra-se claro nas falas a seguir, "o médico não mandou levar o paciente e o solicitante [familiar] pegou e disse assim: 'se vocês não forem levar então tudo bem' e largou os cachorros nos colegas" (P. 1) e "Às vezes chegamos para prestar o atendimento com a maior boa vontade, saímos rápido e arriscamos nossa vida, a cem por hora, passando todos os carros, e aí a gente chega e a população tá reclamando. Tá te agredindo verbalmente" (P. 3).

Muitas vezes, essa situação é gerada pela demora da equipe em chegar ao local ao qual foi chamada. Esse aspecto relaciona-se à forma de funcionamento do serviço, visto que o atendimento depende de uma central de regulação localizada na capital do Estado. Assim, o 
usuário faz a chamada a essa central, os atendentes solicitam informações sobre a vítima e as repassam a um médico que realiza uma triagem. É após esse processo que a ambulância recebe autorização para prestar o atendimento. Essa liberação é realizada pelos despachantes, que fazem contato com a ambulância mais próxima à vítima e informam o caso para os socorristas que irão realizar o atendimento presencial (Marçal, Oliveira, \& Santos, 2009).

Os profissionais precisam esperar a regulação do serviço, tanto para atender aos chamados quanto para remover o paciente. Ao mesmo tempo que a distância da regulação se configura como uma das principais fontes de estresse para os socorristas, ela também exerce um papel de amparo a esses profissionais, uma vez que é quem responde a eventuais problemas decorrentes do atendimento. Esse processo gera ansiedade aos acompanhantes da pessoa que está sob risco de morte. Dessa forma, a demora com a chegada do socorro, muitas vezes é fonte de insatisfação para os usuários, e até mesmo motivo para que estes agridam aos trabalhadores do SAMU, como é ilustrado nos extratos de falas a seguir: ". . O que acontece é que as pessoas perdem um pouco o humor com as situações burocráticas. ..." (P. 2) e,

O problema não é a regulação ser longe, porque é por telefone, então é rápido . . . é que como eles não conhecem a cidade, às vezes dão informações erradas sobre o deslocamento. . . . Aí chegamos lá e não é aquele local, ficamos perdidos, e precisamos encontrar o local sozinho e demora. Com isso, a população reclama, mas estávamos a caminho, tentando encontrar. (P. 3).

A agressão do usuário está relacionada ao desconhecimento da população sobre o funcionamento do SAMU, ou seja, a não compreensão de que os profissionais que prestam o atendimento não possuem autonomia para realizar certos procedimentos. Os solicitantes do serviço - que estão sob forte tensão emocional por estarem diante de uma pessoa em situação de vulnerabilidade - agridem os trabalhadores, contribuindo para aumentar a tensão deles e transformando o contato com o usuário do serviço uma das fontes de estresse.

O fato de a regulação ser em outra cidade está ligado à organização do trabalho, que exerce grande influência sobre a saúde mental do trabalhador. Esta afeta a vida dos trabalhadores e influencia seu modo de vida, apropriando-se do tempo, dos atos e de suas subjetividades. A organização do trabalho é entendida como a divisão das tarefas e dos seres humanos, assim é constituída pela divisão do trabalho, produtividade esperada, regras formais, tempo, controle e características das tarefas (Anjos, 2013).

Os socorristas relataram não possuir um grau satisfatório de autonomia em relação ao seu trabalho. Para Codo, Soratto e Menezes (2004), a possibilidade de controle sobre o trabalho mostra-se como fundamental para que o trabalhador consiga desenvolver e utilizar estratégias para enfrentar as adversidades originadas no trabalho e, consequentemente, evitar o desgaste que dele deriva. Por essa razão, acredita-se que a relação com a regulação central do serviço seja uma das principais fontes de estresse para os participantes do estudo.

O uso inadequado do serviço pelos usuários é outro fator apontado como fonte de estresse. Os trabalhadores relataram que, muitas vezes o SAMU é chamado para realizar remoções ou consultas, atividades que não são, segundo eles, de responsabilidade do serviço. Com isso, atendimentos de urgência deixam de ocorrer, levando à insatisfação da comunidade e, consequentemente, à agressão aos socorristas. Esse aspecto é explicitado na fala a seguir: 
Hoje temos mais estresse no chegar nas pessoas ... tentamos explicar para as pessoas que não é esse o nosso trabalho e muitas vezes somos agredido verbalmente. . . Muitas vezes somos chamados para atender uma pessoa alcoolizada, uma briga de casal, que tu tem que ir lá e não ser socorrista nessa hora e ser psicólogo. (P. 1).

A falta de continuidade no atendimento também foi citada como uma das fontes de estresse. Os trabalhadores possuem a percepção de que o atendimento intra-hospitalar, muitas vezes, difere do atendimento inicial. As vítimas, segundo os socorristas, ao chegarem nos hospitais, nem sempre recebem o atendimento adequado e os trabalhadores do SAMU não podem interferir nessas situações. Um dos participantes relatou a hostilidade dos profissionais de saúde para com os socorristas nos serviços de referência: “. . Normalmente quando chegamos com o paciente em alguns Prontos-Socorros somos mal atendidos. Isso me deixa estressado. Infelizmente, é ruim falar isso, mas os próprios colegas da área da saúde não dão seguimento ao nosso trabalho com o paciente" (P. 1).

Esse dado pode ser entendido como uma fragmentação do trabalho, considerado um dos principais estressores organizacionais nos serviços de assistência (Grazziano \& Bianchi, 2010). No SAMU, os trabalhadores são responsáveis pelo atendimento até a chegada em uma unidade de referência, o que os impede, consequentemente, de tomar conhecimento da evolução do caso, levando a certo grau de alienação em relação ao trabalho prestado. As organizações de saúde envolvem muitos profissionais, tornando-se um desafio contemplar os interesses da coletividade, as necessidades dos usuários e dos grupos de saúde. A fragmentação das atividades dentro de campos profissionais leva a mudanças relacionadas ao controle sobre o processo de trabalho e a autonomia (Scherer, Pires, \& Schwartz, 2009).

\section{Estratégias de Defesa}

As estratégias de defesa são mecanismos utilizados pelo indivíduo com o intuito de modificar, transformar e minimizar a percepção da realidade que lhe causa sofrimento e, assim, permitir que mantenham o equilíbrio psíquico (Barros \& Mendes, 2003). No caso dos participantes do estudo, as estratégias defensivas constituem-se em recursos utilizados para protegê-los de vivências de sofrimento relacionadas ao labor e, assim, evitar que adoeçam. Contudo, muitas vezes, as condições de trabalho não são adequadas para dar conta das demandas do serviço. Essa situação pode ser percebida na fala de um dos trabalhadores:

... O trânsito, se você não é uma pessoa muito tranquila, te estressa e sai da ambulância e acaba brigando com as pessoas ... na Avenida $X$, que tu tem que ir para o hospital $Y$ num momento de pico, se você não tiver paciência, dá vontade de arrancar os carros da frente com as mãos. (P. 1).

Diante de situações diárias, como a descrita pelo P1, as principais estratégias de defesa identificadas nas falas dos socorristas do SAMU, para minimizar os efeitos das situações enfrentadas, são: a habituação, a prática de atividade física, a convivência familiar e o fato de gostar do trabalho realizado. A habituação, relacionada ao tempo de serviço e à experiência em trabalho de urgência e emergência, foi ressaltada pelos participantes. É possível perceber que, devido à convivência diária com situações com forte potencial para gerar o estresse, os trabalhadores se acostumam com elas e naturalmente deixam de sentir o desconforto 
que é causado nos primeiros tempos de atividade, "Eu já tenho cinco anos de SAMU ... no primeiro ano tu fica mais eufórico, né ... a adrenalina sobe mais" (P. 1) e "Hoje eu já tenho alguma experiência e já sei o que fazer, estou há dois anos no SAMU, mas eu trabalho com emergência há muito tempo" (P. 3).

A habituação pode ser definida como a diminuição espontânea e progressiva das respostas a um estímulo, ocorre quando se permanece em contato com ele por um período de tempo longo ou quando este é repetidamente apresentado. É um fenômeno natural e responsável por minimizar ou anular as sensações desagradáveis provadas por determinados estímulos (Cordioli, 2014). Esse mecanismo colabora para que os trabalhadores do serviço de atendimento móvel de urgência mantenham um bom nível de saúde.

A prática da atividade física foi citada por três, dos quatro participantes da pesquisa, como um importante recurso que os auxilia a enfrentar as demandas impostas pelo cotidiano do trabalho. São exemplos as falas a seguir, "Caminhada, saio com os amigos, vou, por exemplo, quando tenho folga, domingo à tardinha no lugar X caminhar" (P. 4), "Faço atividade física ... vou pra academia e lá eu esqueço tudo" (P. 1) e "Fazia tênis e corrida, agora não estou conseguindo tempo, mas com certeza a atividade física é muito importante" (P. 3).

A atividade física é uma forma de lazer e contribui para restaurar a saúde dos efeitos negativos de uma rotina de trabalho estressante (Silva, Silva, Silva, Souza, \& Tomasi, 2010). A prática regular de exercício físico contribui para desenvolver o condicionamento cardíaco, que leva a uma diminuição na corrente sanguínea de substâncias associadas ao estresse. Os benefícios da prática continuada de exercícios físicos abrangem também os aspectos psicossociais, sendo que a interação social e a comunicação interpessoal podem servir de estratégias para lidar com situações geradoras de estresse (Paschoal \& Tamayo, 2005). Somado a isso, a pesquisa de Adriano et al. (2017) indica que a idade pode ser um fator que contribua para que o organismo resista com mais vigor aos agentes estressores, como menor experiência profissional possibilita o aumento do interesse pelo trabalho, assim como motivação e vontade de aprender e aperfeiçoá-lo, características compatíveis aos participantes.

Outro recurso importante apontado pelos participantes do estudo no enfrentamento das vivências percebidas como estressantes é o apoio e suporte da família. Três sujeitos da pesquisa citaram esse recurso como sendo fundamental no alívio das tensões decorrentes de suas profissões. Seguem os trechos de fala que ilustram o suporte familiar, "Chegar em casa, ser recebido pela esposa, conversar e falar um pouco sobre como foi o seu dia. . . . Ajuda, com certeza" (P. 3) e "Tenho família e um neto que me distrai bastante. É outro recurso, antes eu tomava medicação por causa do bruxismo, sinto que depois que ele [neto] nasceu, até isso diminuiu. E isso é um dos 'escapes' que eu tenho" (P. 4).

A relação entre família e estresse ocupacional é citada por Rocha, Almeida, Silva, e Vaz (2011) em pesquisa realizada com o objetivo de mensurar as influências, entre vida familiar e a atividade profissional. Este estudo mostrou que há uma relação positiva entre essas variáveis, ou seja, a existência de afeto nas relações familiares constitui-se em um fator que apodera os sujeitos, fornecendo maior autoconfiança para o desenvolvimento das laborais. Os pesquisadores observaram que a família é capaz de proporcionar um ambiente de descanso e de suporte para o enfrentamento dos desafios profissionais (Rocha et al., 2011).

O suporte familiar pode ser entendido como manifestações de atenção, carinho, diálogo, liberdade e proximidade existente entre os integrantes da família (Baptista \& Oliveira, 2004). 
Dessa forma, os membros do grupo familiar sentem-se amados, valorizados, compreendidos e reconhecidos, o que faz com que, à medida que percebam esse suporte, encontrem forças para enfrentar situações adversas. Esse aspecto traz consequências positivas para o bem-estar do indivíduo, entre elas a redução do estresse, o aumento da autoestima e do bem-estar psicológico (Souza, Baptista, \& Alves, 2008).

Outra estratégia defensiva citada por todos os socorristas foi o gostar do trabalho que realizam. Esse aspecto mostra-se fundamental para a estruturação do sentido do trabalho e está intimamente relacionado à satisfação com o trabalho, que pode ser definida como o estado emocional de prazer, resultante de múltiplos fatores relacionados ao trabalho, capazes de afetar a relação do trabalhador para consigo mesmo e para com a organização do trabalho (Melo, Barbosa, \& Souza, 2011). Esse conceito inclui o componente cognitivo, a percepção de que trabalho vai ao encontro das necessidades pessoais dos trabalhadores e ainda o componente afetivo que os profissionais depositam em sua atividade laboral (Oliveira \& Spiri, 2011). O gostar do trabalho foi observado claramente na fala de todos os participantes do estudo, "Se for pelo salário, a gente não trabalha no SAMU, a gente trabalha mais porque gosta . . . isso não é uma opção, isso é um amor, de fazer e ajudar as pessoas" (P. 1) e "Eu gosto de trabalhar no SAMU, gosto do pré-hospitalar, trabalho aqui porque me identifico ... 99,9\% das pessoas trabalham aqui porque amam o pré-hospitalar e gostam de exercer essa atividade" (P. 2).

$\mathrm{Na}$ análise das falas, ficou evidente que os socorristas do SAMU estudados permanecem em um nível de saúde mental aparentemente bom e protegem-se dos efeitos nocivos do estresse, principalmente, por gostarem do trabalho que realizam. Esse fator é também apontado como a principal motivação entre os enfermeiros, em pesquisa realizada para identificação dos fatores de motivação e de insatisfação no trabalho (Baptista, Vieira, Cardoso, \& Carvalho, 2005). Ainda vale pontuar que as pessoas desenvolvem as estratégias ao longo do tempo e as utilizam ou não, dependendo das circunstâncias vivenciadas. A presença de tais recursos ou o uso adequado destes podem estar associados a aspectos individuais nas esferas biológica, social, psicológica e espiritual (Lipp \& Malagris, 2011). Embora os tipos de estratégias defensivas sejam algo da ordem do individual, as identificadas no estudo em questão mostraram-se comuns aos trabalhadores pesquisados.

\section{Considerações Finais}

O trabalho e as atuais demandas sociais impostas aos sujeitos são um dos principais fatores desencadeantes do estresse, acarretando prejuízos à saúde física e mental. Neste estudo, apenas uma trabalhadora do SAMU apresentou sintomas significativos de estresse, predominantemente psicológicos e na fase de resistência. Ao considerar que os sujeitos do estudo estão no serviço há no mínimo dois anos e convivem, diariamente, com situações semelhantes, pode-se inferir que a percepção de estresse, bem como a presença de seus sinais, pode ser influenciada pela questão de gênero. Todavia, embora haja evidências de pesquisas anteriores sobre as repercussões entre estresse e gênero, são necessários mais estudos para afirmar essa relação. Outra lacuna encontrada neste estudo, que incita uma nova investigação científica, surge do seguinte questionamento: é possível comparar o estresse entre profissionais de diferentes categorias, pertencentes a um mesmo serviço? 
É possível presumir que esses socorristas não apresentaram sintomas de estresse, pois suas atividades diárias não são monótonas e repetitivas, pois cada atendimento possui características singulares. Diante dos fatores percebidos como potencialmente estressantes, destacam-se o contato com o usuário, a dependência da central de regulação para a realização de certos procedimentos (relacionados à organização do trabalho) e o mau uso do serviço pela população. Porém, de acordo com os participantes, algumas ações já estão sendo pensadas para minimizar os problemas relacionados ao uso inadequado. Como exemplo, foi citada a conscientização da população acerca dos serviços prestados pelo SAMU através da mídia.

Os participantes consideraram boa a gestão do serviço e afirmaram que sempre são atendidos quando necessitam de materiais para o bom desempenho do trabalho, embora pontuassem que existe demora no atendimento de tais solicitações. Para os participantes, a lentidão se deve ao fato da burocracia existente, visto que o SAMU funciona com verba tripartite, ou seja, depende de recursos financeiros dos governos federal, estadual e municipal.

A aparente saúde física e mental desses trabalhadores deve-se, sobretudo, às estratégias de defesa que possuem e que permite a convivência saudável com as situações ansiogênicas. Dentre os recursos citados, identificaram-se com maior prevalência a habituação, a prática de atividade física, a convivência familiar e o gostar do trabalho que realizam. Este último recurso foi citado por todos os socorristas participantes do estudo.

Embora a pesquisa tenha atingido os objetivos propostos, vale ressaltar que está aquém da compreensão desejada acerca do estresse ocupacional, posto que é amplo e abarca múltiplas variáveis e questões que não puderam ser contempladas neste trabalho. Mesmo que um estudo qualitativo não exija um grande amostral, apenas quatro entrevistados - sendo um de cada uma das categorias profissionais que compõem uma equipe- mostra-se como o grande limitador da possibilidade de generalização deste estudo. Assim, novos estudos com profissionais de urgência e emergência devem ser realizados para que se possa contribuir com a manutenção ou com o restabelecimento da saúde física e mental desses profissionais, já que a integridade desses aspectos garante o atendimento adequado e de boa qualidade para a comunidade na qual o SAMU está inserido. O aporte teórico da psicologia sobre o tema ainda se mostra escasso, visto que a maior parte dos estudos sobre o estresse e saúde ocupacional é realizada na área da enfermagem.

\section{Referências}

Adriano, M. S. P. F., Almeida, M. R., Ramalho, P. P. L., Costa, I. P., Nascimento, A. R. S., \& Moraes, J. C. O. (2017). Estresse ocupacional em profissionais da saúde que atuam no Serviço de Atendimento Móvel de Urgência de Cajazeiras - PB. Revista Brasileira de Ciências da Saúde, 21(1), 29-34. doi: 10.4034/RBCS.2017.21.01.04

Anjos, F. B. (2013). Organização do trabalho. In F. O. Vieira, A. M. Mendes, \& A. R. C. Merlo (Org.),

Dicionário crítico de gestão e psicodinâmica do trabalho (pp. 267-274). Curitiba: Juruá.

Antunes, R. (2003). Os sentidos do trabalho: Ensaio sobre a afirmação e negação do trabalho

(6a reimp.). São Paulo: Boitempo Editorial.

Baptista, M., \& Oliveira, A. (2004). Sintomatologia de depressão e suporte familiar em adolescentes: um estudo de correlação. Revista Brasileira de Crescimento e Desenvolvimento Humano, 14(3), 58-67. Disponível em http://www.revistas.usp.br/jhgd/article/view/40168 
Baptista, A. A. V., Vieira, M. J., Cardoso, N. C. S. \& Carvalho, G. R. P. (2005) Fatores de motivação e insatisfação no trabalho do enfermeiro. Revista da Escola de Enfermagem da USP, 39(1), 85-91. doi: 10.1590/S0080-62342005000100011

Barros, P. C. R., \& Mendes, A. M. B. (2003). Sofrimento psíquico no trabalho e estratégias defensivas dos operários terceirizados da construção civil. Psico-USF, 8(1), 63-70. doi: 10.1590/S1413-82712003000100009

Borges, L. O., \& Yamamoto, O. H. (2014). Mundo do trabalho: Construção histórica e desafios contemporâneos. In J. C. Zanelli, J. Borges-Andrade, \& A. V. B. Bastos, Psicologia, organizações e trabalho no Brasil (2a ed.), (pp. 25-72). Porto Alegre: ArtMed.

Breakwell, G., Fife-Schaw, C., Hammond, \& Smith, J. (2010). Métodos de pesquisa em Psicologia (3a ed.). Porto Alegre: Artmed.

Calais, S. L., Andrade, L. M. B., \& Lipp, M. E. N. (2003). Diferenças de sexo e escolaridade na manifestação de stress em adultos jovens. Psicologia: Reflexão e Crítica, 16(2), 257-263. doi: 10.1590/S0102-79722003000200005

Codo, W., Soratto, L., \& Menezes, I. V. (2004). Saúde mental e trabalho. In J. C. Zanelli, J. E., Borges-Andrade, \& A. V. B. Bastos (Org.), Psicologia, organizações e trabalho no Brasil. Porto Alegre: Artmed.

Cordioli, A. V. (Org.). (2014). TOC: Manual de Terapia Cognitivo-Comportamental para o Transtorno Obsessivo Compulsivo (2a ed.). Porto Alegre: Artmed.

Fontana, R. T., \& Siqueira, K. I. (2009). O trabalho do enfermeiro em saúde coletiva e o estresse: Análise de uma realidade. Cogitare Enfermagem, 14(3), 491-498. doi: 10.5380/ ce.v14i3.16179

Grazziano, E. S., \& Bianchi, E. R. (2010). Impacto do stress ocupacional e burnout para enfermeiros. Enfermería Global, 18, 1-20. doi: 10.4321/S1695-61412010000100020

Lipp, M. E. N. (2005). Manual do Inventário de Sintomas de Stress para Adultos de Lipp (ISSL) (3a ed.). São Paulo: Casa do Psicólogo.

Lipp. M. E. N., \& Malagris, L. E. N. (2011). Estresse. In B. Rangé, \& cols. Psicoterapias cognitivocomportamentais: Um diálogo com a psiquiatria (2a ed.), (pp. 617-632). Porto Alegre: Artmed.

Marcelino, D., Figueiras, M. J., \& Claudino, A. (2012). Impacto da exposição a incidentes críticos na saúde e bem-estar psicológico dos tripulantes de ambulância. Psicologia, Saúde \& Doenças, 13(1), 110-116. Disponível em http://www.scielo.mec.pt/pdf/psd/ v13n1/v13n1a10.pdf

Marçal, M. A., Oliveira, K., \& Santos, E. (2009). Estudo da relação entre a carga mental e o nível de estresse ocupacional em motoristas socorristas do SAMU. Anais do XV Congresso Brasileiro de Ergonomia - Associação Brasileira de Ergonomia ABERGO. Porto Seguro, BA, Brasil. Disponível em http://www.nersat.com.br/qualidade-de-vida-no-trabalho/estudoda-relacao-entre-a-carga-mental-e-o-nivel-de-estresse-ocupacional-em-motoristassocorristas-do-samu/

Melo, M. B., Barbosa, M. A., \& Souza, P. R. (2011). Satisfação no trabalho da equipe de enfermagem: revisão integrativa. Revista Latino-Americana de Enfermagem, 19(4), 1-9. Disponível em http://www.revistas.usp.br/rlae/article/view/4413

Meneghini, F., Paz, A. A., \& Lautert, L. (2011). Fatores ocupacionais associados aos componentes da síndrome de burnout em trabalhadores de enfermagem. Texto \& Contexto - Enfermagem, 20(2), 225-233. doi: 10.1590/s0104-07072011000200002 
Minayo, M. C. de S. (2010). O desafio do conhecimento (12a ed.). São Paulo: Hucitec.

Oliveira, J., \& Lipp, M. E. N. (2009). Resiliência e controle do stress em juízes e servidores públicos. Boletim da Academia Paulista de Psicologia, 77(9), 287-306. Disponível em http:// pepsic.bvsalud.org/scielo.php?script=sci_arttext\&pid=S1415-711X2009000200007

Oliveira, E. M., \& Spiri, W. C. (2011). Dimensão pessoal do processo de trabalho para enfermeiras de Unidades de Terapia Intensiva. Acta Paulista de Enfermagem, 24(4), 550555. doi: 10.1590/s0103-21002011000400016

Paschoal, T., \& Tamayo, Á. (2005). Impacto dos valores laborais e da interferência família - Trabalho no estresse ocupacional. Psicologia: Teoria e Pesquisa, 21(2), 173-180. doi: 10.1590/s0102-37722005000200007

Pereira, C. A., Miranda, L. C. S., \& Passos, J. P. (2010). O estresse e seus fatores determinantes na concepção dos graduandos de Enfermagem. Reme - Revista Mineira de Enfermagem, 14(2), 204-209. doi: 10.1590/S1415-27622010000200009

Rocha, L. P., Almeida, M. C. V., Silva, M. R. S., \& Vaz, M. R. C. (2011). Influência recíproca entre atividade profissional e vida familiar: percepção de pais/mães. Acta Paulista de Enfermagem, 24(3), 373-380. doi: 10.1590/s0103-21002011000300011

Sadir, M. A., Bignotto, M. M., \& Lipp, M. E. N. (2010). Stress e qualidade de vida: Influência de algumas variáveis pessoais. Paideia, 20(45), 73-81. doi: 10.1590/ s0103-863×2010000100010

Scherer, M. D. A., Pires, D., \& Schwartz, Y. (2009). Trabalho coletivo: Um desafio para a gestão em saúde. Revista de Saúde Pública, 43(4), 721-725. doi: 10.1590/s0034-89102009000400020

Schmidt, D. R., Dantas, R. A., \& Marziale, M. H. (2011). Anxiety and depression among nursing professionals who work in surgical units. Revista da Escola de Enfermagem da USP, 45(2), 487-493. doi: https://dx.doi.org/10.1590/S0080-62342011000200026

Seleghim, M. R., Mombelli, M. A., Oliveira, M. L. F., Waidman, M. A. P., \& Sonia, S. M. (2012). Sintomas de estresse em trabalhadoras de enfermagem de uma unidade de pronto socorro. Revista Gaúcha de Enfermagem, 33(3), 165-173. doi: http://dx.doi.org/10.1590/ S1983-14472012000300022

Silva, E. A. T., \& Martinez, A. (2005). Diferença em nível de stress em duas amostras: Capital e interior do estado de São Paulo. Estudos de Psicologia, 22(1), 53-61. doi 10.1590/ S0103-166X2005000100007

Silva, R. S., Silva, I., Silva, R. A., Souza, L., \& Tomasi, E. (2010). Atividade física e qualidade de vida. Ciência \& Saúde Coletiva, 15(1), 115-120. Disponível em http://dms.ufpel.edu.br/ ares/handle/123456789/289

Souza, M. S., Baptista, M. N., \& Alves, G. A. S. (2008). Suporte familiar e saúde mental: Evidência de validade baseada na relação entre variáveis. Aletheia, 28, 45-59. Disponível em http:// pepsic.bvsalud.org/scielo.php?script=sci_arttext\&pid=S1413-03942008000200005

Souza, N. V. D. O., Correia, L. M., Cunha, L. S., Eccard, J., Patrício, R. A., Antunes, T. C. S. (2011). O egresso de enfermagem da FENF/UERJ no mundo do trabalho. Revista da Escola de Enfermagem da USP, 45(1), 250-257. doi: http://dx.doi.org/10.1590/ S0080-62342011000100035

Sousa, V. F. S., \& Araújo, T. C. C. F. (2015). Estresse ocupacional e resiliência entre profissionais de saúde. Psicologia: Ciência e Profissão, 35(3), 900-915. doi: http://dx.doi. org/10.1590/1982-370300452014. 
Talarico, J. N. S., Carmelli, P., Nitrini, R., \& Chaves, E. C. (2009). Sintomas de estresse e estratégias de copping em idosos saudáveis. Revista da Escola de Enfermagem da USP, 43(4), 803-809. doi: 10.1590/s0080-62342009000400010

Recebido em: 10/08/2017

Última revisão: 10/10/2017

Aceite final: 11/10/2017

\section{Sobre as autoras:}

Daiane Granada Martins - Especialista em Psicologia do Trabalho e das Organizações pela Universidade Franciscano (UFN). Psicóloga pela Faculdade Integrada de Santa Maria (FISMA). E-mail: daianegranada@hotmail.com, Orcid: http://orcid.org/0000-0001-7784-8606

Júlia Gonçalves - Doutora em Psicologia pela Universidade Federal de Santa Catarina (UFSC). Mestre em Psicologia pela Universidade Federal de Santa Maria (UFSM). Psicóloga pelo Universidade Francisca (UFN). Professora do Curso de Graduação em Psicologia da Faculdade Meridional (IMED) e membro no Núcleo de Estudos de Processos Psicossociais e de Saúde nas Organizações e no Trabalho (NEPPOT/UFSC).E-mail: julia_psi_@hotmail.com, Orcid: http://orcid.org/0000-0002-2804-1045 
